\title{
Recycling of Waste Engine Oils Using Different Acids as Washing Agents
}

\author{
Salah Eldeen F. Hegazi ${ }^{1,2}$, Yasir A. Mohamd ${ }^{1}$, Mohammed Ibrahim Hassan ${ }^{2}$ \\ ${ }^{1}$ Department of Chemical Engineering, Elimam Elmahdi University, Kosti, Sudan \\ ${ }^{2}$ Department of Chemical Engineering, Jazan University, Jazan, Saudi Arabia
}

Email address:

salahhegazi2003@yahoo.com (S. E. F. Hegazi)

To cite this article:

Salah Eldeen F. Hegazi, Yasir A. Mohamd, Mohammed Ibrahim Hassan. Recycling of Waste Engine Oils Using Different Acids as Washing Agents. International Journal of Oil, Gas and Coal Engineering. Vol. 5, No. 5, 2017, pp. 69-74. doi: 10.11648/j.ogce.20170505.11

Received: February 3, 2017; Accepted: February 27, 2017; Published: October 23, 2017

\begin{abstract}
This paper addresses recycling of waste engine oils treated using by (acetic acid and formic acid). A recycling process was developed which eventually led to comparable results with some of the conventional methods. This gives the recycled oil the potential to be reused in cars' engines after adding the required additives. The advantage of using the (acetic acid or formic acid) is that it does not react or only reacts slightly with base oils. The recycling process takes place at room temperature. It has been shown that base oils and oils' additives are slightly affected by the acetic acid. Upon adding (acetic acid or formic acid) to the used oil, two layers were separated, a transparent dark red colored oil and a black dark sludge at the bottom of the container. The base oils resulting from other recycling methods were compared to the results of the fresh oil. The comparison showed that the recycled oil produced by acetic acid and formic acid treatment showed excellent results in the properties of the oil comparable to the fresh oil. Using volumetric ratio of 10:1 oil to acetic acid result in density $0.87 \mathrm{~g} / \mathrm{ml}$ and this close to fresh oil mean while using ratio of 10:1 oil to formic acid result in viscosity $30 \mathrm{cp}$ and this equivalent to fresh oil.
\end{abstract}

Keywords: Recycle, Used Oil, Treatment, Acetic Acid, Formic Acid, Fresh Oil, Additives

\section{Introduction}

Waste engine oil is a high pollutant material that requires responsible management. Waste engine oil may cause damage to the environment when dumped into the ground or into water streams including sewers. This may result in groundwater and soil contamination [1]. Recycling of such contaminated materials will be beneficial in reducing engine oil costs. In addition, it will have a significant positive impact on the environment [2-4]. The conventional methods of recycling of waste engine oil either requires a high cost technology such as vacuum distillation or the use of toxic materials such as sulfuric acid. These methods also produce contaminating byproducts which have highly sulfur levels. Lubricant oils have been used primarily for reducing friction between moving parts of various machinery or equipment, minimize material wear, improve the efficiency of equipment /machinery and for fuel and energy savings. Access to lubricants is essential to any modern society and not only does lubrication reduce friction and wear by interposition of a thin liquid film between moving surfaces, but it also removes heat, keeps equipment clean, and prevents corrosion [5]. Waste lubricating oil refers to the engine oil, transmission oil, hydraulic and cutting oils after use. It is also refers to the degradation of the fresh lubricating components that become contaminated by metals, ash, carbon residue, water, varnish, gums, and other contaminating materials, in addition to asphaltic compounds which result from the bearing surface of the engines [6]. This oils must be changed and removed from the automobile after a few thousand kilometers of driving because of stress from serious deterioration in service. The amount of lubricating oils that is collected annually in Europe and USA is very large, approximately 1.7 to 3.5 million tons. This large amount of waste engine oils has a significant impact on both economic and environmental aspects. They cost millions of dollars to manufacture and represent a high pollutant material when disposed. If discharged into the land, water or even burnt as a low grade fuel, this may cause serious pollution problems because they release harmful metals and other pollutants into the environment [7].

The main service properties of Engine oil are their 
viscosity, viscosity - temperature properties, fluidity at low temperatures, chemical stability and protective properties. Lubricating oils have viscosities ranging from 10 to 1000 centistokes at $100^{\circ} \mathrm{F}[12]$.

A recommended solution for this problem is the recovery of the lubricating oil from the waste oil. Recycling processes using nontoxic and cost effective materials can be an optimum solution.

\section{Objectives}

- Achieve the optimum conditions of recycling the waste lubricant oil through adding different volumetric ratio of acetic acid to the base oil.

- Obtain a high quality of lubricant oil that comply the specification of standard methods.

- Keep environment from hazards that caused by mismanagement of used oils.

- Provide engine oil to local market with good quality and low price which leads to economic growth.

\section{Methodology}

\subsection{Stages of Acid Treatment}

$300 \mathrm{ml}$ of used engine oil was measured by measuring cylinder and transferred into a $500 \mathrm{ml}$ beaker. Also, $30 \mathrm{ml}$ of acids (acetic acid, formic acid) was measured in a separate $50 \mathrm{ml}$ beaker. The regulator hot plate was switched on and the measured base oil was placed on top. The temperature of the base oil (used engine oil) was maintained at $40-45^{\circ} \mathrm{C}$. At this temperature the (acetic acid, formic acid) were introduced into the used engine oil simultaneously with stirring of the mixture for 10 minutes.

\subsection{Sedimentation /Decantation}

At the end of the acid treatment step, the acidic oil was allowed to settle 24 hours to form sediment at the bottom of the beaker. After this period, the acidic-oil was properly sediment and was decanted into Another $500 \mathrm{ml}$ beaker using piece of cloth while the residue (acidic sludge) at the bottom of the beaker was discarded.

\subsection{Bleaching}

The acidic oil in the beaker was subjected to bleaching. The oil was placed on a regulator hot plate and the temperature was maintained at a temperature of $110^{\circ} \mathrm{C}$. $6 \mathrm{wt} \%$ of activated bleaching earth was introduced into the oil and the mixture was continuously stirred for 15 minutes. At the end of the bleaching step, the bleached oil was neutralized.

\subsection{Neutralization}

The bleached oil was neutralized to adjust the $\mathrm{pH}$ of the oil to neutrality. At this step, $4 \mathrm{wt} \%$ of the oil of sodium hydroxide was introduced into the bleached oil by taken into consideration the $\mathrm{pH}$ of the bleached oil at a given point in time. The bleached oil was neutralized with a continuous manual stirring for 10 minutes. At the end of the bleaching and neutralization steps, the oil was allowed to sediment in the beaker for 24 hours and was decanted into the beaker, while the residue at the bottom of beaker was discarded.

\subsection{Sedimentation /Decantation}

During this stage, the oil was allowed to settled in the beaker for 24 hours and was decanted into another beaker, while the residue at the bottom of the beaker was discarded.

\subsection{Filtration}

The sediment oil was finally filtered using a filter cloth and the filtrate was collected in a filtration flask and was observed to be clear while, the residue (filter cake) was discarded.

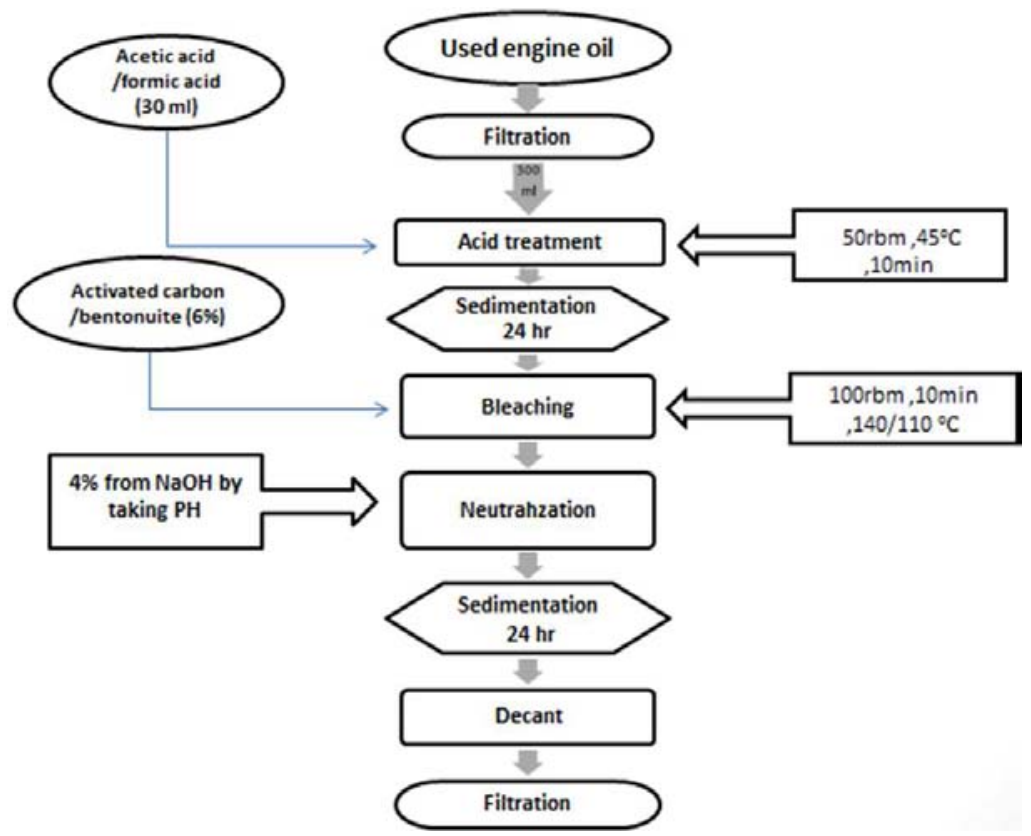

Figure 1. Block diagram of recycling of used engine oil. 


\section{Results \& Discussions}

Table 1. Specific gravity, viscosity of fresh oil, used oil and treated oils with formic and acetic acid.

\begin{tabular}{lll}
\hline Oil Type & Density $(\mathbf{g} / \mathbf{m l})$ & Viscosity $\mathbf{c p}$ \\
\hline Fresh oil & 0.87 & 30 \\
Used Engine Oil & 0.91 & 16 \\
Treated Oil with acetic acid & 0.87 & 28 \\
Treated Oil with formic acid & 0.864 & 30 \\
\hline
\end{tabular}

In table (1) compare between the fresh oil, used engine oil and treated oil with formic and acetic acid by the density and viscosity.

We note that the treated oil with acetic acid the density is the closest to fresh oil, and the treated oil with formic acid the viscosity was close to fresh oil, at ratio of oil to acetic acid and formic acid 10:1

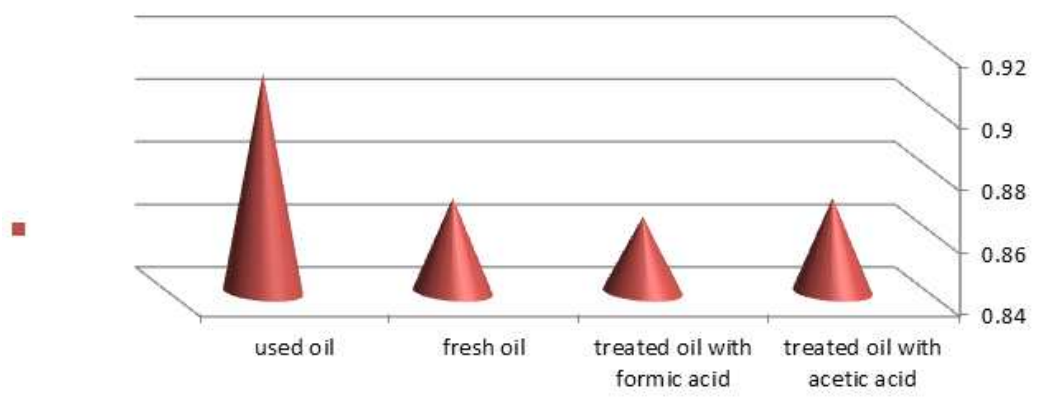

Figure 2. Specific gravity of fresh oil, used oil and treated oils with formic and acetic acid.

In figure (2) the specific gravity of the used oil was observed higher compared to the fresh oil, because the specific gravity of the used oil increase with oil combustion in the engine with the fuel, which results in impurities, than the specific gravity is increase. Once the used oil is treated with the formic acid, and acetic acid; the specific gravity increased. This experiment conducted at oil: acid ratio but we did after our plugin acid from 10:1

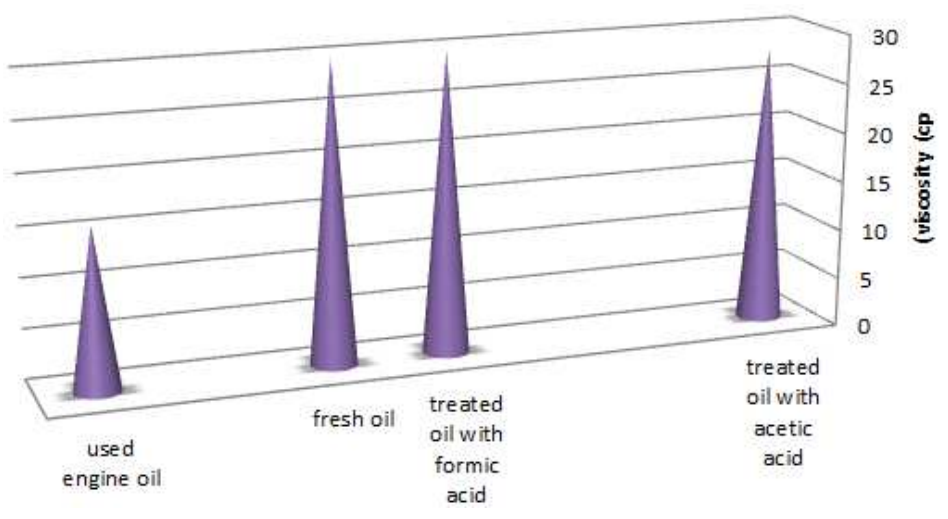

Figure 3. Viscosity of fresh oil, used oil and treated oils with formic and acetic acid.

In figure (3) the viscosity of the used oil was observed lower when it compared to the fresh oil, because the viscosity of the used oil decrease with oil combustion in the engine with the fuel, which results in impurities, the results showed the treated oil with formic acid and acetic acid closed to the fresh oil and this indicates the efficient of using acid treatment. The experiment conducted at same ratio 10:1

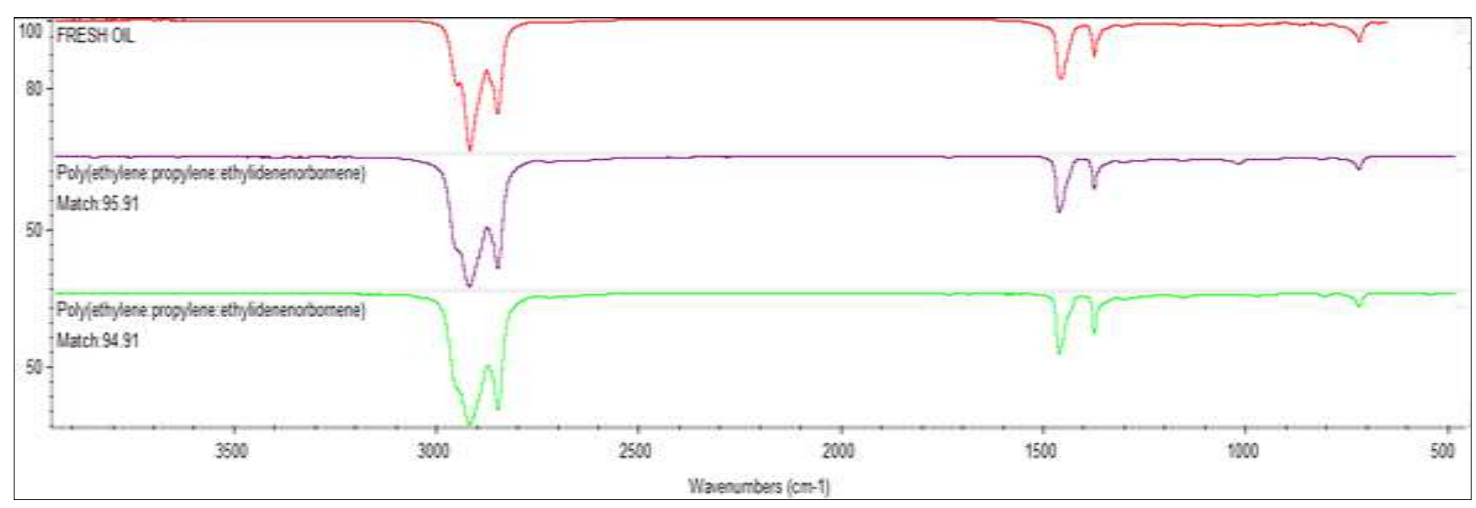

Figure 4. Chemical composition of fresh oil. 
Figure (4) showed the chemical composition of the fresh oil. The FTIR results compared to the components that the synthesis used oil is close to vinyl (ethylene propylene ethylene dennenbomen) approximates to $95.91 \%$.

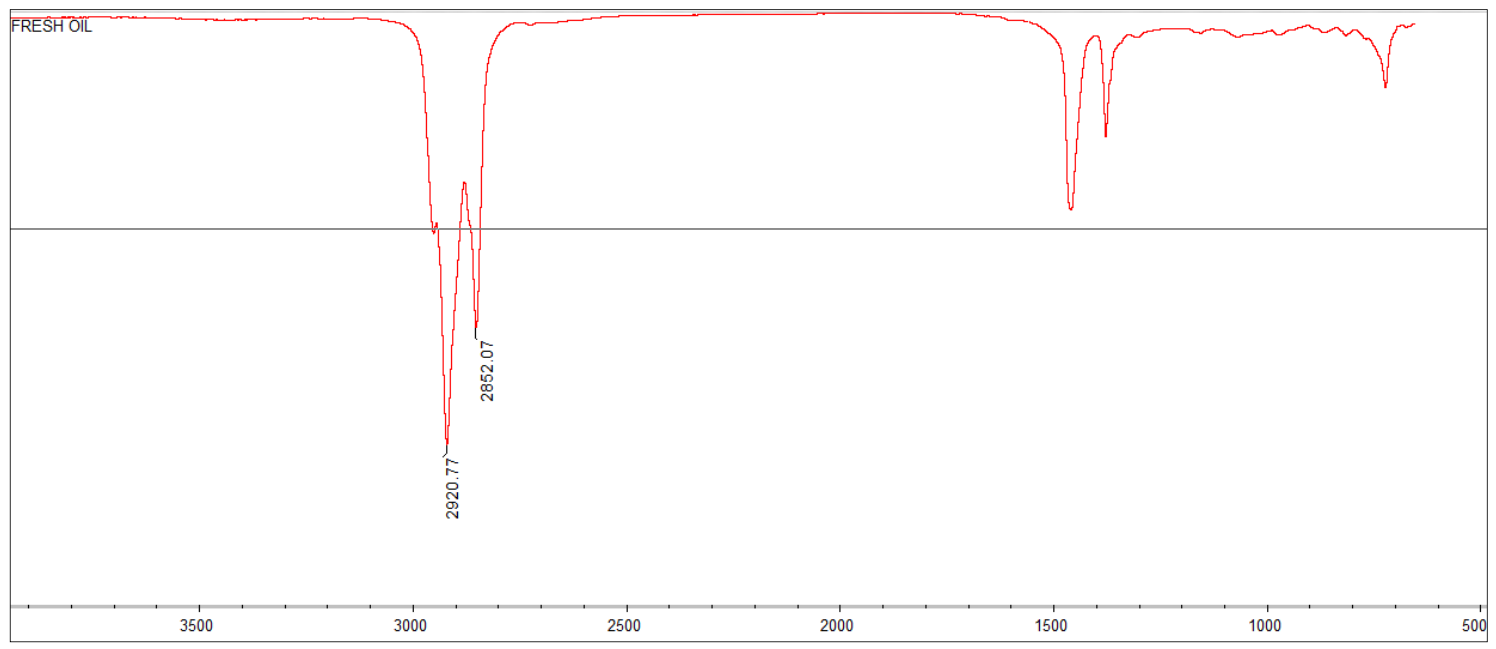

Figure 5. Peaks of the fresh oil.

FTIR spectra for fresh oil showed additional peaks at 2920.77 and $2852.07 \mathrm{~cm}-1$ which represent the primary oxidized products at high temperatures. The fresh oil showed some oxidized components as illustrated in Figure (5).

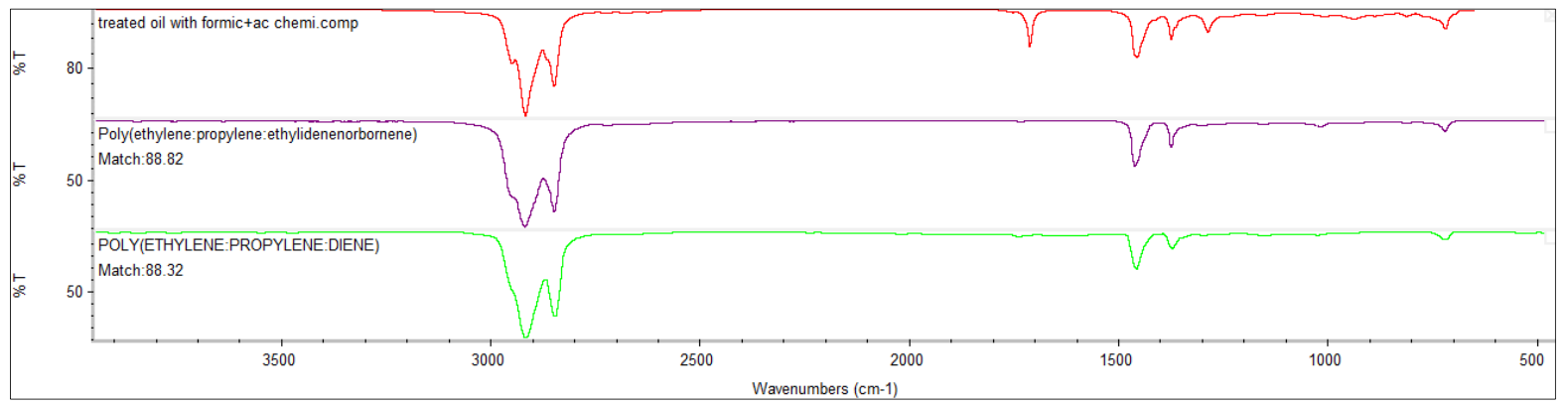

Figure 6. Treated oil with formic acid and bleached with activated carbon chemical composition.

In figure (6) showed the chemical composition of the used oil. The FTIR results compared to the components that the synthesis used oil is close to vinyl (ethylene propylene ethylene dennenbomen) approximates to $88.32 \%$.

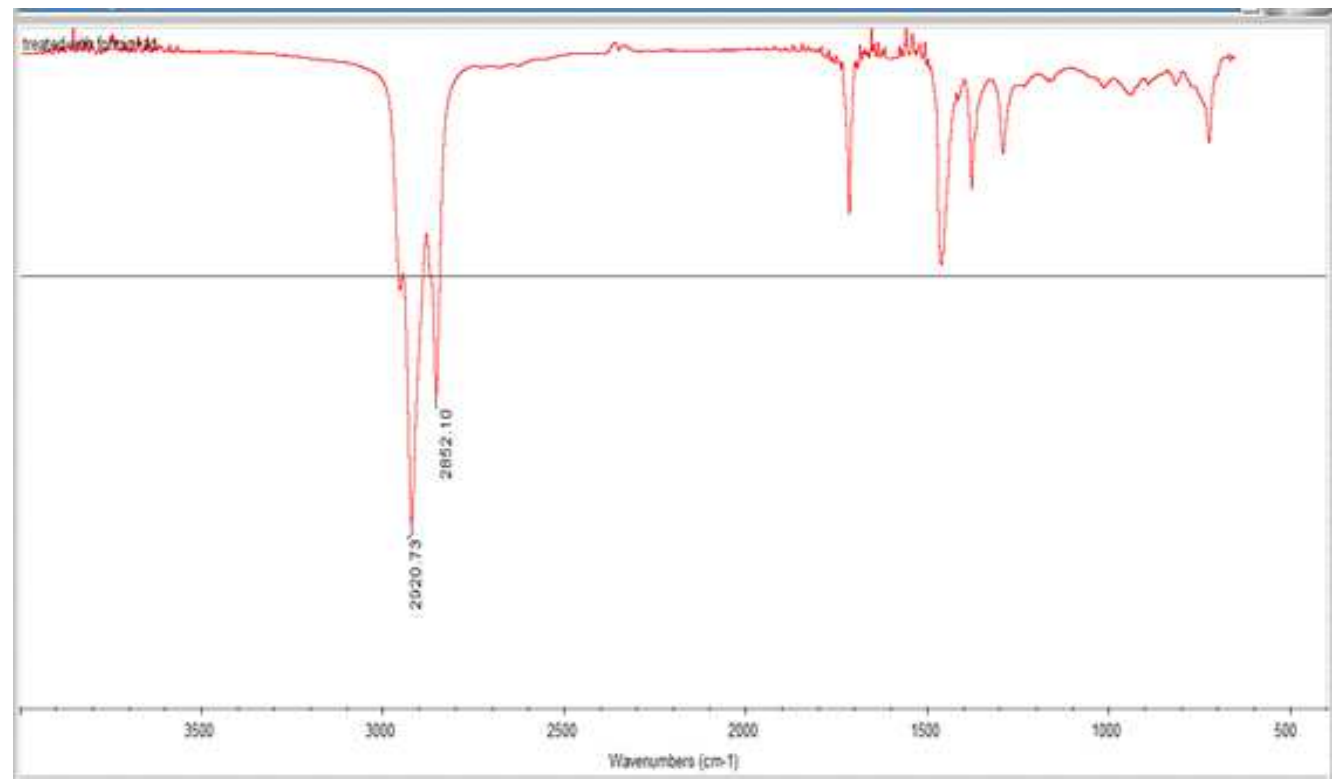

Figure 7. Peaks of Treated oil with formic acid bleached with activated carbon. 
FTIR spectra for used engine oil showed additional peaks at 2020.75 and $2852.10 \mathrm{~cm}-1$ which represent the primary oxidized products at high temperatures. The used oil treated by the formic acid bleached with activated carbon method still showed some oxidized components as illustrated in Figure (7).

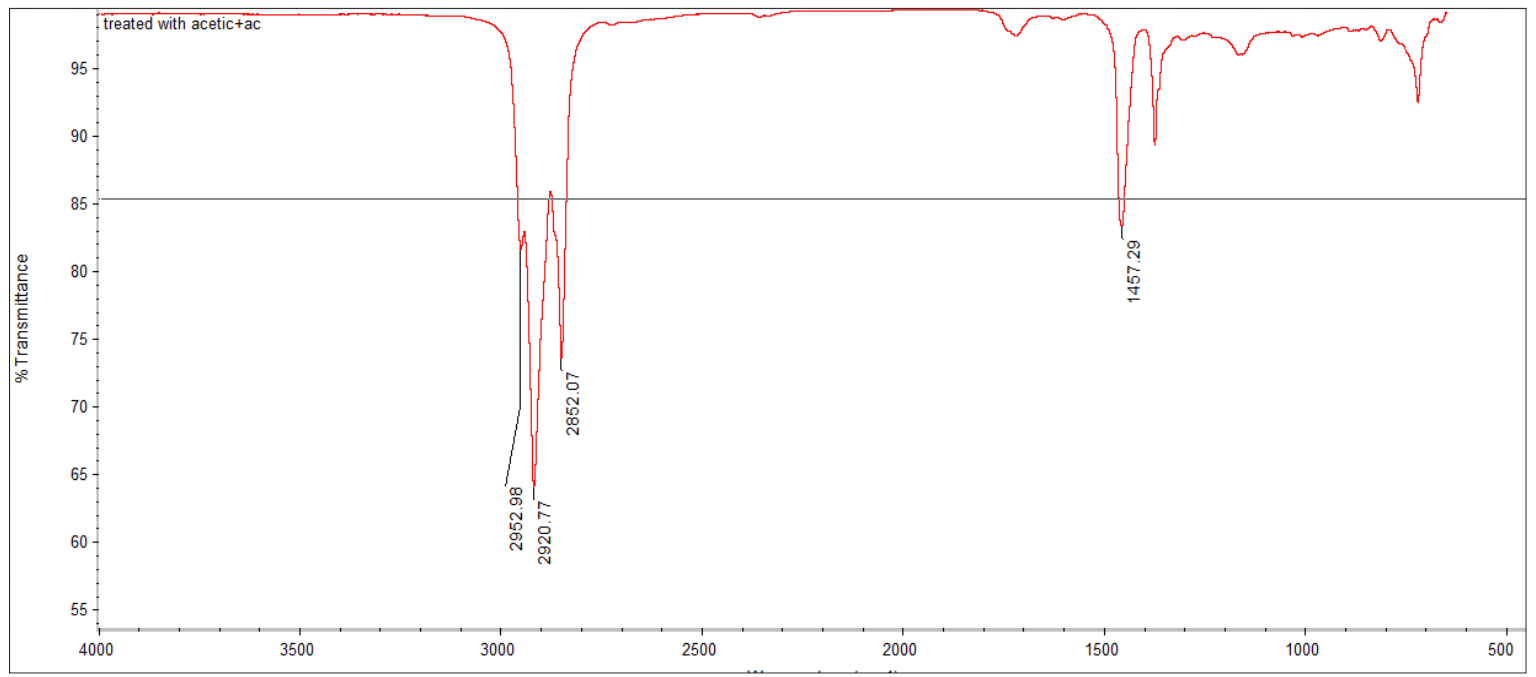

Figure 8. Peaks of Treated oil with acetic acid bleached with activated carbon.

FTIR spectra for used engine oil showed additional peaks at 2952.98, 292.77, 2852.07 and $1457.29 \mathrm{~cm}-1$ which represent the primary oxidized products at high temperatures. The used oil treated by the acetic acid bleached with activated carbon method still showed some oxidized components as illustrated in Figure (8).

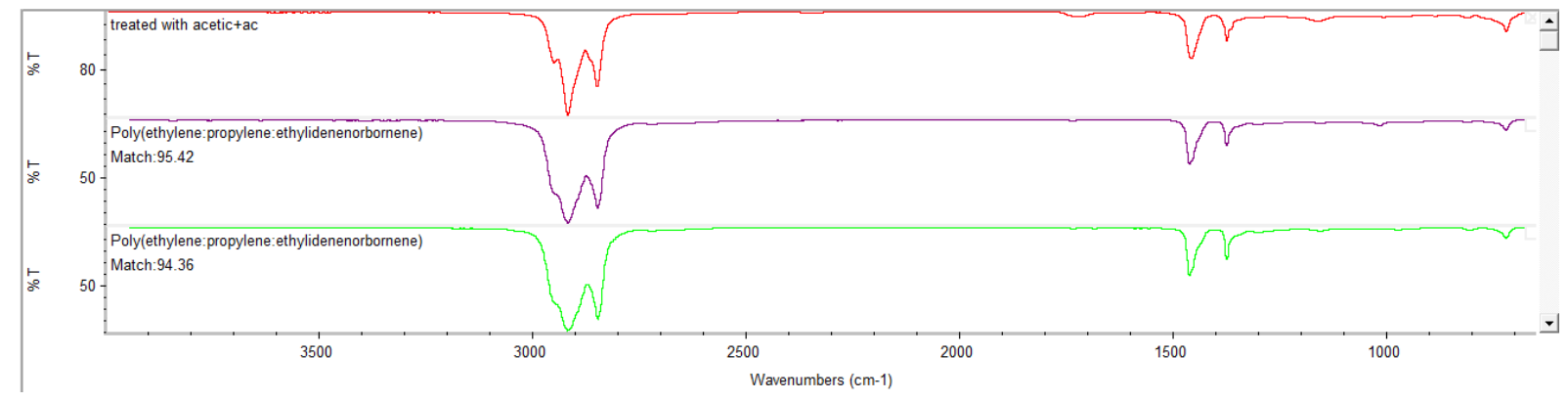

Figure 9. Chemical composition of Treated oil with acetic acid bleached with activated carbon.

In Figure (9) showed the chemical composition of the used oil. The FTIR results compared to the components that the synthesis used oil is close to vinyl (ethylene propylene ethylene dennenbomen) approximates to $95.42 \%$.

\section{Conclusion}

The glacial acetic acid and formic acid have shown almost no reaction with base oils, in contrast to sulfuric acid, however it reacted vigorously with the used oil. This clearly indicates that acetic acid and formic acids are not affecting the original structure of the oil. Furthermore, this is most advantageous of using acetic acid and formic acids in recycling of used oil. This new process of recycling of used engine oil did not emit poisonous gases like sulfur dioxide to the atmosphere. In addition, glacial acetic acid and formic acids have less of a negative impact on the processing equipment compared with sulfuric acid. Lower amount of additives may be required for the base oil recycled by acetic acid-clay method due its low reactivity with the used oil. Further research is required in order to take this process to the commercial stage. However, while many variables have been studied in this research, there are many others that need investigation such as temperature, pressure, settling time, mixing, centrifugation speed and type of adsorbent.

\section{Recommendation}

a Applying acid treatment in the industry due to the least cost compared to the vacuum distillation and solvent extraction method.

b Select acetic acid and formic acids in the used engine oil for the effective separating of the sludge and contaminates.

c Further studies should focus on sludge analysis. 


\section{References}

[1] Hopmans, J. J. Report for the European Economic Community (EEC); National Institute for Wastewater Treatment: Dordrecht, The Netherlands, 1974.

[2] Kajdas, C. Major pathways for used oil disposal and recycling, Part. 2000, 7, 61-74.

[3] Boughton, B.; Horvath, A. Environmental assessment of waste oil management methods. 2004, 38, 353-358.

[4] IARC (International Agency for Research on Cancer). Polynuclear Aromatic Hydrocarbons, Part 2, Carbon Blacks, Mineral Oils (Lubricant Base Oils and Derived Products) and Some Nitroarenes.

[5] Francois, A. Waste Engine Oils Refining and Energy Recovery, 1st ed.; Elsevier Science and Technology Books: Amsterdam, The Netherlands, 2006; pp. 15-31.

[6] Whisman, M. L.; Reynolds, J. W.; Goetzinger, J. W.; Cotton, F. O.; Brinkman, D. W. Re-refining makes quality oils. Hydrocarb. Process. 1978, 57, 141-145.

[7] Reis, M. A. R.; Jeronimo, M. S. Waste lubricating oil rerefining by extraction-flocculation. 1988, 27, 1222-1228.

[8] Fox, M. F. Sustainability and environmental aspects of lubricants., George, E. D., Totten, E., Eds.; Taylor and Francis: New York, NY, USA, 2007.

[9] Rincon, J.; Canizares, P.; Garcia, M. T. Regeneration of used lubricating oil by polar solvent extraction. 2005, 44, 43-73.

[10] Rincon, J.; Canizares, P.; Garcia, M. T. Waste oil recycling using mixtures of polar solvents. 2005, 44, 7854-7859.

[11] Shakirullah, M.; Ahmed, I.; Saeed, M.; Khan, M. A., Rehman, H.; Ishaq, M.; Shah, A. A. Environmentally friendly recovery and characterization of oil from used engine lubricants 2006, $53,335-342$.

[12] Isah, A. G., Abdulkadir, M., Onifade, K. R., Musa, U., Garba, M. U., Bawa, A. A and Sani, Y., Regeneration of Used Engine Oil, Proceedings of the World Congress on Engineering 2013 Vol I, WCE 2013, July 3 - 5, 2013, London, U. K. 